Laser Chem. 1986, Vol. 6, pp. 125-147

0278-6273/86/0602-0125\$12.00/0

(C) harwood academic publishers $\mathrm{GmbH}$

Printed in Great Britain

\title{
LASER INDUCED CHEMICAL REACTIONS IN COMBUSTION \\ AND INDUSTRIAL PROCESSES
}

\author{
J. WOLFRUM \\ Physikalisch-Chemisches Institut \\ der Puprecht-Karls-Universität \\ D-6900 Heidelberg, Im Neuenheimer Feld 253 \\ and \\ Max-Planck-Institut für strömungsforschung \\ D-3400 Göttingen, Böttingerstrasse 6-8 \\ West-Germay
}

The rapid development of powerful UV-laser sources allows the investigation of macroscopic and microscopic details of elementary chemical reactions important in combustion processes. Experimental results on the effect of selective translational and vibrational excitation of reactants in elementary combustion reactions using laser photolysis and time-resolved atomic line resonance absorption, laserinduced fluorescence and CARS spectroscopy are compared with the results of theoretical studies on ab initio potential energy surfaces and thermal rate parameters. Thermal elimination of hydrogen chloride from 1,2-dichloroethane and $1,1,1$-chlorodifluoroethane is a main industrial route to some important monomer compounds. Inducing thic radical chain reactions by UV-exciplex laser radiation offers the advantage that a monomolecular process with low activation energy becomes the rate determining step. This allows lower process timperatures with decreasing energy expense and avoiding the high temperature formation of by products.

\section{INTRODUCTION}

It has been known, since the first use of fire by mankind , that the rates of chemical reactions depend strongly of the energy of the reactants. Traditionally, the energy dependence of the chemi- 
cal reaction rate is studied under conditions in which the rate of reaction is slow compared to that of collisional energy transfer. Under these conditions, the energy of the reactants is characterized by a temperature. The temperature variation of the reaction rate can then often be expressed with sufficient accuracy by the Arrhenius equation. The Arrhenius parameters obtained in this way, however, contain no direct information on how the various degrees of freedom of the reacting molecules and in the "activated complex" contribute to the potential pathways of product formation in the chemical reaction. Investigations on the chemical reactivity under a wide range of conditions such as pressure variation and specific excitation of the reactants give important insights into the microscopic dynamics of the chemical reaction. This information on one hand can be compared with the results of theoretical predictions using potential energy surfaces for chemical reactions obtained by $\mathrm{ab}$ initio methods, and is also of basic interest to improve the kinetic data used in detailed chemical kinetic modelling of combustion processes. The experimental possibilities to study elementary chemical reactions in detail have expanded quite dramatically in recent years as a result of the development of various laser sources. The coherence, collimation, monochromaticity, polarization, tunability and short pulse duration of laser light sources now available in the infrared, visible, and ultraviolet region allow the preparation and detection of chemically reacting molecules with an unprecedented degree of selectivity.

The precent paper cannot give a comprehensive collection of experimental and theoretical results in this field. Instead, a number of typical examples is presented. The first part gives specific examples of experimental and theoretical investigations with selective translational and vibrational exctation of the reactants. The second part describes studies on the formation of vinylchloride 
and vinylidenfluoride by UV laser-induced chain reactions.

THE EFFECT OF TRANSLATIONAL EXCITATION

Despite the large number of elementary steps taking place even in the oxidation of simple hydrocarbons, important parameters of the combustion process are controlled by relatively few elementary reactions. As shown in Figure 1 in the case of the oxidation of methane, ethane and butane the flame velocities calculated by detailled chemical kinetic modelling are relatively insensitive to reactions specific for the oxidation of these molecules ${ }^{2}$. However, there is a strong influence on the calculated flame velocity by a number of unspecific reactions such as

$$
\begin{aligned}
& \mathrm{H}+\mathrm{O}_{2} \rightleftharpoons \mathrm{OH}+\mathrm{O} \\
& \mathrm{CO}+\mathrm{OH} \rightleftharpoons \mathrm{CO}_{2}+\mathrm{H} \\
& \mathrm{OH}+\mathrm{H}_{2} \rightleftharpoons \mathrm{H}_{2} \mathrm{O}+\mathrm{H}
\end{aligned}
$$

At least in one direction considerable collision energies are necessary to surmount the reaction barrier in these elementary steps. The dynamics of such high barrier reactions can be studied in microscopic details by combining translationally hot atom and radical formation by laser photolysis (forming reactants with initially high and monoenergetic collision energies) with time and state resolved product detection by laser-induced fluorescence spectroscopy ${ }^{3-5}$. The experimental apparatus is shown in Figure 2. Fig. 3 gives nascent rotational state distributions for the reactions(1), $(-2)$, and $(-3)$ at relative collision energies around $250 \mathrm{~kJ} / \mathrm{mol}$. Despite of comparable total reaction energies, the nascent $\mathrm{OH}(\mathrm{v}=0)$ rotational distributions are quite different. The distribution is extremely hot from the $\mathrm{H}+\mathrm{O}_{2}$ reaction, broadly peaked at rotational quantum numbers around $\mathrm{K}=11$ in the $\mathrm{H}+\mathrm{CO}_{2}$ case and restricted to low values with only $3 \%$ of the total available energy partitioned into rotation for the $\mathrm{H}+\mathrm{H}_{2} \mathrm{O}$ system. The obsered rotational 


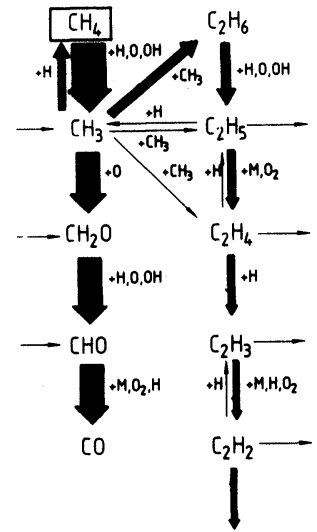

STOICHIOMETRIC

$V_{u}\left(k_{i}\right) / V_{u}\left(\frac{1}{5} k_{j}\right) \longrightarrow$

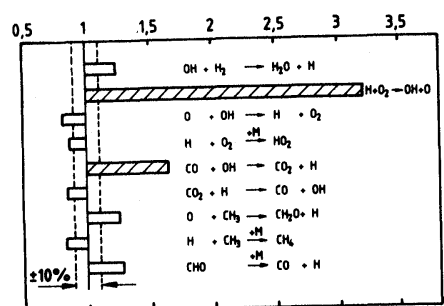

$\mathrm{CH}_{4} /$ AIR

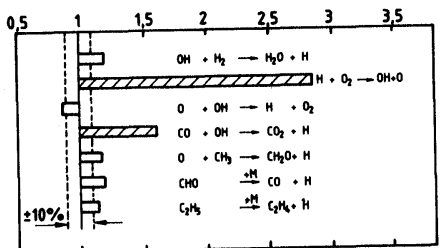

$\mathrm{C}_{2} \mathrm{H}_{6} / \mathrm{AIR}$

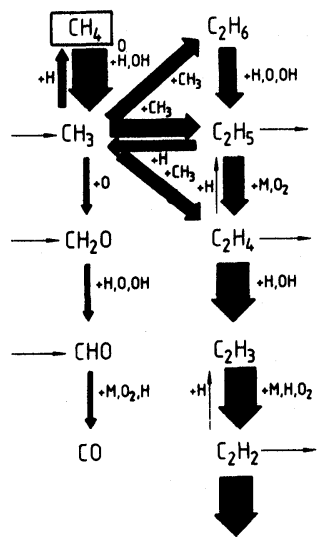

$\mathrm{RICH}$

$V_{u}\left(k_{i}\right) / V_{u}\left(\frac{1}{5} k_{i}\right) \longrightarrow$

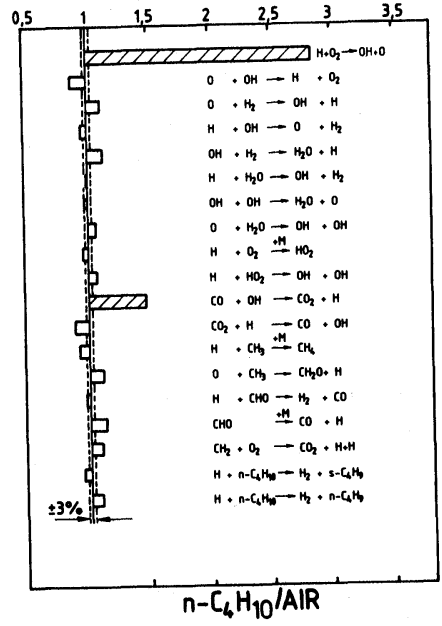

FIGURE 1 Molar chemical fluxes in atmospheric $\mathrm{CH}_{4}$-air flames and Sensitivity of calculated free flame velocity $\left(v_{u}\right)$ on the reduction of elementary rate coefficients by a factor of five $^{2}$. 


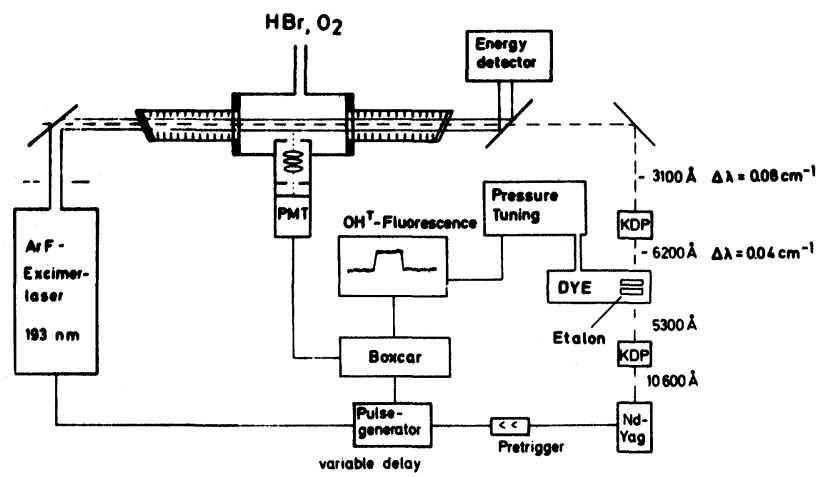

FIGURE 2 Schematic of experimental arrangement for the study of radical reactions with substantial threshold energies.

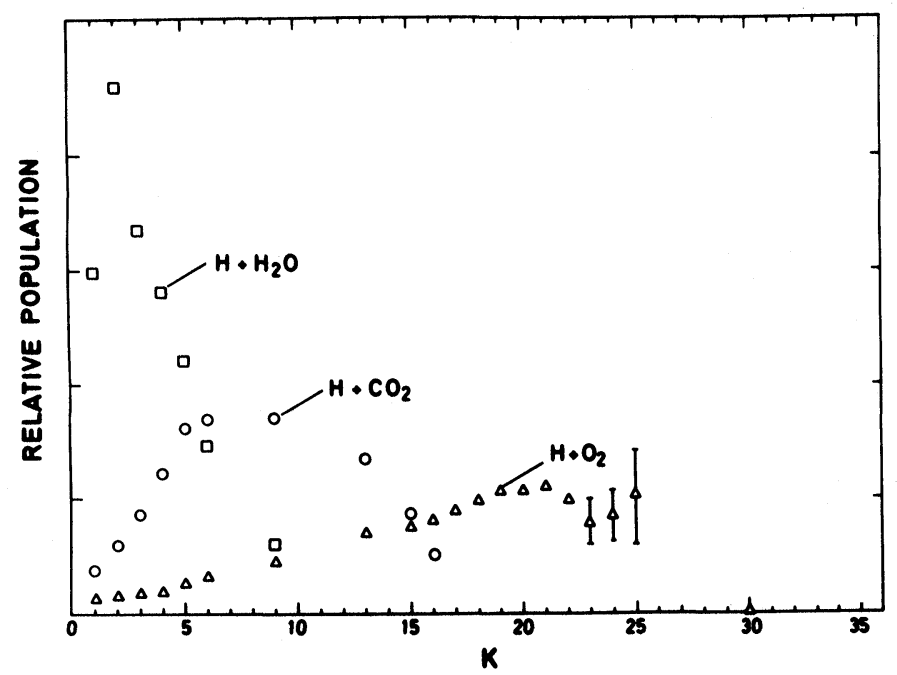

FIGURE 3 Nascent rotational state distribution in $\mathrm{OH}(\mathrm{V}=0)$ produced in the reactions $(1),(-2)$, and $(-3)$ at relative collision energies of $250 \mathrm{~kJ} / \mathrm{mol}$. $\mathrm{K}$ is rotational quantum number. 
energy distributions give interesting microscopic details on the molecular dynamics of these elementary steps. Spin-orbit and orbital-rotation interactions in the $\mathrm{OH}$ radical cause fine-structure splittings for each rotational level. Each of these fine structure levels can be probed by different rotational sub-bands. As shown in Table $I$, the two of spin states ${ }^{2} \Pi_{1 / 2}$ and ${ }^{2} \Pi_{3 / 2}$ are, within experimental error, equally populated. However, the $\boldsymbol{\Lambda}$-doublet fine structure states show a clear preference for the lower energy $\Pi^{+}$component. The experimental result shows that the break-up of the reaction complex generates forces in a plane containing the bond to be broken. $\mathrm{OH}$ rotates in that plane and $\mathrm{J}_{\mathrm{OH}}$ is perpendicular to it and to the broken bond. This picture is consistent only with a preferential planar excit channel in these reactions. This could also be directly demonstrated using polarized photolysis and analysis laser beams ${ }^{6}$.

TABLE I Measured absolute reaction cross sections, vibrational and fine structure partitioning for rotational levels of $\mathrm{OH}$ produced in the reactions $(1),(-2)$, and $(-3)$

\begin{tabular}{llll}
\hline & $\mathrm{H}+\mathrm{H}_{2} \mathrm{O}$ & $\mathrm{H}+\mathrm{CO}_{2}$ & $\mathrm{H}+\mathrm{O}_{2}$ \\
\hline $\begin{array}{l}\mathrm{E}_{\mathrm{COII}}^{\mathrm{C} . \mathrm{m}}[\mathrm{kcal} / \mathrm{mol}] \\
\sigma\left[\AA^{2}\right]\end{array}$ & 58.2 & 60.1 & 60.7 \\
$\frac{\sigma(\mathrm{v}=1)}{\sigma(\mathrm{v}=0)}$ & $0.24 \pm 0.1$ & $0.37 \pm 0.1$ & $0.42 \pm 0.2$ \\
$\frac{\sigma\left({ }^{2} \Pi_{3 / 2}\right)}{\sigma\left({ }^{2} \Pi_{1 / 2}\right)} \frac{\mathrm{K}}{\mathrm{K}+1}$ & $1.1 \pm 0.2$ & $\leqslant 0.1$ & $0.47 \pm 0.15$ \\
$\frac{\sigma\left(\Pi^{+}\right)}{\sigma\left(\Pi^{-}\right)}$ & $3.2 \pm 1.0$ & $3.0 \pm 1.0$ & $1.2 \pm 0.2$ \\
\hline
\end{tabular}

Reaction (1) is known to take place adiabatically on the ground state potential surface of the $\mathrm{HO}_{2}\left({ }^{2} \mathrm{~A} "\right)$-radical. Trajectory 
calculations $^{7}$ on an ab initio surface (Melius-Blint ${ }^{8}$ ) are in agreement with calculated $\mathrm{OH}$ rotational distributions from the phase space theory ${ }^{9}$ for low relative translational energy. With increasing relative translational energy the oH rotational distribution becomes is considerably hotter than the statistical one, and no long living $\mathrm{HO}_{2}-$ complex excists during the reaction. As given in Table I the experimental total reaction cross section at $\mathrm{E}_{\mathrm{T}}=$ $254 \mathrm{~kJ} / \mathrm{mol}$ is $0.42 \pm 0.2[\AA]^{2}$ for reaction (1). The theoretical cross section obtained under this condition by quasi classical quantum mechanical threshold calculations ${ }^{10}$ at the Melius-Blint surface is $0.38[\AA]^{2}$. These numbers cannot be compared directly because the multiplicity of the ${ }^{2} \mathrm{~A}^{\prime \prime}$-surface at infinite $\mathrm{H}-\mathrm{O}_{2}$ separation is not taken into account. Miller ${ }^{10}$ uses a multiplicity factor of $1 / 3$. This would yield a theoretical cross section of $0.13[\AA]^{2}$ which is significantly outside the experimental range. Calculated rate coefficients using this theoretical cross section ${ }^{10}$ are in agreement with shock tube measurements of the rate of reaction (1) by Schott 11 and Chiang and Skinner ${ }^{11}$. However, as shown in Figure 4, very recent shock tube experiments by Just and Frank ${ }^{12}$ using time resolved atomic resonance line absorption coincide with the extrapolated values recommended by Baulch et al. ${ }^{13}$. Even higher rate data for $k_{1}$ are reported by Bowman ${ }^{14}$. Also in the recombination pathway

$$
\mathrm{H}+\mathrm{O}_{2} \longrightarrow \mathrm{HO}_{2} * \stackrel{+\mathrm{M}}{\longrightarrow} \mathrm{HO}_{2}
$$

new measurements of the high prssure limit recombination rate coefficient $^{15}$ are higher than calculated values ${ }^{16}$. The observed discrepancies could be attributed to a reduction of calculated reactive cross sections due to a "rigid" character and a barrier of $8 \mathrm{~kJ} / \mathrm{mol}$ of the Melius-Blint surface for dissociation of the $\mathrm{HO}_{2}$ in reaction $(-1 a)^{15}$. Calculations by Dunning et al. ${ }^{17}$ reduce this barrier to less than $1.7 \mathrm{~kJ} / \mathrm{mol}$. Also for reaction $(-1 \mathrm{a})$ the 


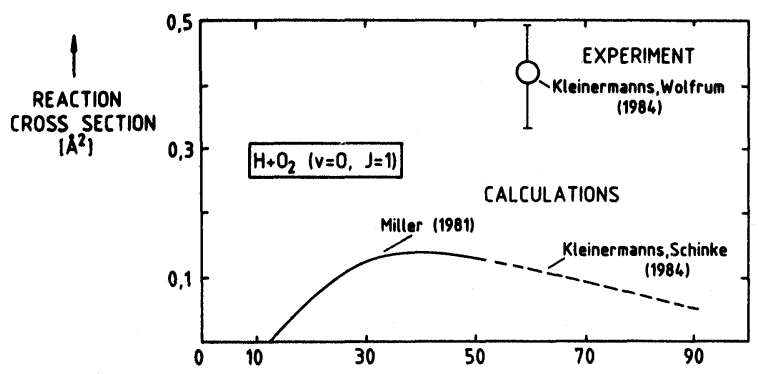

RELATIVE TRANSLATIONAL ENERGY $[\mathrm{kcal} / \mathrm{mol}]$ -

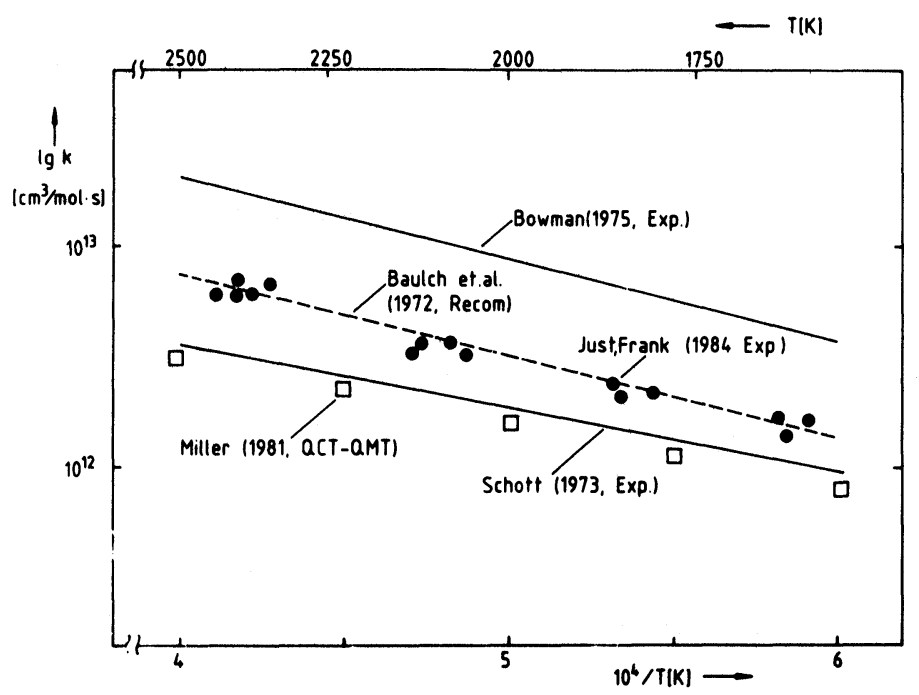

FIGURE 4 Measured and calculated reaction cross sections ana thermal rate coefficients for reaction $\mathrm{H}+\mathrm{O}_{2} \rightarrow \mathrm{OH}+\mathrm{O}$

Melius-Blint surface apparently overestimates the long range $\mathrm{O}-\mathrm{OH}$ $\operatorname{attracion}^{18}$ while the Quack-Troe interpolation scheme ${ }^{19}$ leads to better agreement with the experimental values at low temperatures 20 .

In summary, it is encouraging to see that recent microscopic and macroscopic experimental data start to give a more converging picture on this reaction central for all combustion modellin cal- 
culations. However, more work should be done on the potential energy surface used for this system. Further experiments should be directed to additional thermal rate data measurements in the high temperature range and measurements of absolute reaction cross sections at different collision energies.

\section{THE EFFECT OF VIBRATIONAL EXCITATION}

The exchange reaction between the hydrogen atom and the hydrogen molecule provides the simplest case where for neutral species the effect of vibrational exctation on the kinetic process of bond breaking under the influence of new bond formation can be studied experimentally and theoretically. As shown in Figure 5, single vibrational quantum excitation of the $\mathrm{H}_{2}$-molecule exceeds the Arrhenius activation energy $\left(E_{a}\right)$, the threshold energy $\left(E_{0}\right)$ as well as the potential energy barrier height $\left(\mathrm{E}_{C}\right)$ of the reaction $\mathrm{D}+\mathrm{H}_{2}$. More than half a century ago, London ${ }^{21}$ was the first who pointed out that the potential energy of the $\mathrm{H}_{3}$ system can be expressed in terms of three coulombic interaction integrals and three exchange integrals. As shown in Figure 5, this simle valence bond calcula-

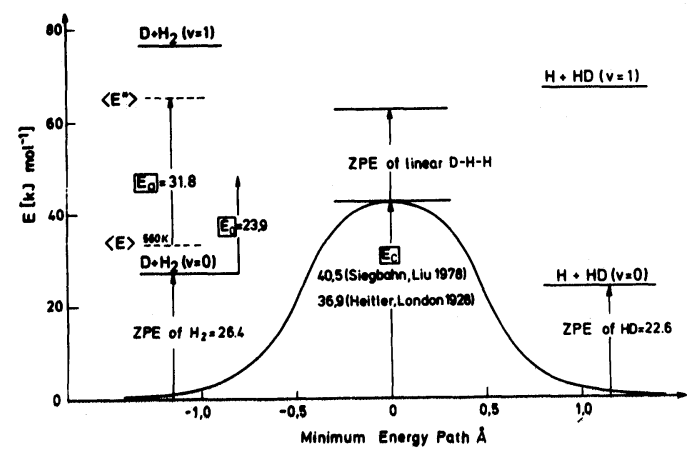

FIGURE 5 Characteristic energies for the $\mathrm{D}+\mathrm{H}_{2}$ (v) reaction 
tion leads to a potential energy barrier $\mathrm{E}_{\mathrm{C}}=36.9 \mathrm{~kJ} / \mathrm{mol}$, not far from the result obtained with modern high speed electronic computing devices ${ }^{22}$. However, a more precise treatment of the London method including contributions resulting from everlap and three center terms destroys the good, accidental agreement with modern results. In order of 1500 thoroughlyly selected ab initio points were calculated by Siegbahn and $\mathrm{Liu}^{22}$ and fitted to an analytical function which represents the potential energy hypersurface mathematically in a smooth and easily handable way by Truhlar and Horowitz ${ }^{23}$. Experiments on the effect of vibrational excitation of the rate of the hydrogen atom exchange reaction were hampered by the difficulties in preparing and measuring known concentrations of vibrationally excited hydrogen molecules. The methods used include thermal generation of $\mathrm{H}_{2}(\mathrm{v}=1)$ combined with a hydrogen maser technique $^{24}$, energy transfer from laser excited $\mathrm{HF}(\mathrm{v}=1)$ combined with Lyman-a resonance absorption ${ }^{25}$, microwave descharge generation of $\mathrm{H}_{2}(\mathrm{v}=1)$ combined with ESR spectroscopy ${ }^{26}$, and Lyman- $\alpha$ resonance absorption $^{27}$. Figure 6 shows results of direct measurements of the temperature dependence of the reaction

$$
\mathrm{D}+\mathrm{H}_{2}(\mathrm{~V}=1) \longrightarrow \mathrm{HD}(\mathrm{V}=0,1)+\mathrm{H}
$$

using CARS spectroscopy for the detection of $\mathrm{H}_{2}(\mathrm{v})-$ molecules ${ }^{27}$. A distinct temperature dependence is observed in the experiments which compares well with the theoretical calculations performed recently using the SLTH ab initio surface and different methods for treating the dynamics of the chemical reaction.

In calculations using quantised periodic orbits a barrier of $18.3 \mathrm{~kJ} / \mathrm{mol}$ has been found in the entrance channel of the $\mathrm{v}=1$ adiabatic surface far from the saddle point 28,29 in good agreement with recent exact quantum calculations $30,32,33$ and quasi-classical trajectory studies ${ }^{31}$. There is also good agreement of theory and experiment in the case of $\mathrm{D}+\mathrm{H}_{2}(\mathrm{v}=0)$ and $\mathrm{H}+\mathrm{D}_{2}(\mathrm{v}=0)$ reactions with 


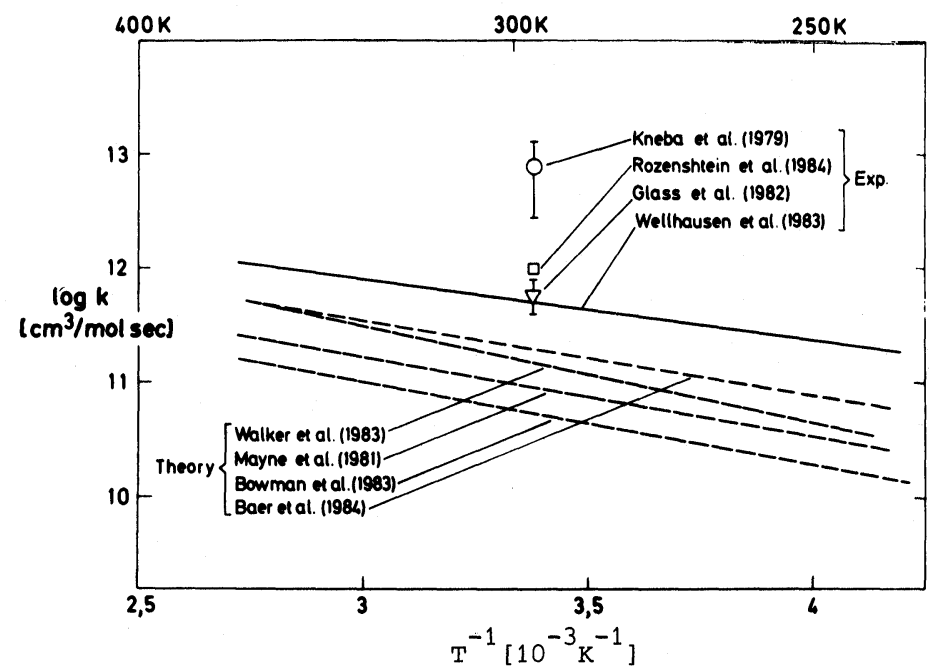

FIGURE 6 Comparison of experimental and calculated rate constants for the reaction $\mathrm{D}+\mathrm{H}_{2}(\mathrm{v}=1)$

high translational energy of the reactants ${ }^{34-37}$. This indicates that the SLTH surface 23 is correct even at high energies where only a few ab-initio points wre calculated. On the other hand, there are still significant discrepancies for the absolute values of the $\mathrm{H}+\mathrm{H}_{2}(\mathrm{~V}=1)$ rate coefficients between theory and experiments as well as between the different theoretical treatments. The disagreement between theory and experiment for this reaction which should be the best-understood of all chemical processes surely provides a continuing theoretical and experimental challenge.

\section{UV-LASER INDUCED RADICAL-CHAIN REACTIONS}

This part descibes application of RGH lasers to investigate the mechanism and kinetics of the photo-initiated chain reaction in 1,2-dichloroethane - (DCE) to form vinyl chloride (VC), and in $1,1,1$-chlorodifluoroethane (CDFE) to form vinylidene fluoride (VDF). The reactions are of considerable industrial importance, 
being the main route to production of vinyl chloride and vinylidene fluoride monomer feedstock for the manufacture of polymers.

Thermal dehydrochlorination of DCE, first observed by $\mathrm{H}$. Biltz in $1902^{38}$, is started by the highly endothermic $\mathrm{C}-\mathrm{Cl}$ bond rupture in the substrate molecule, followed by the chain consisting of hydrogen abstraction from the substrate by $\mathrm{Cl}$ atoms and the unimolecule decomposition of the resulting 1,2-dichloroethyl radicals.

$$
\begin{array}{lll}
\mathrm{CH}_{2} \mathrm{ClCH}_{2} \mathrm{Cl} & \longrightarrow \mathrm{CH}_{2} \mathrm{ClCH}_{2}+\mathrm{Cl} \Delta \mathrm{H}=334 \mathrm{~kJ} / \mathrm{mol} \\
\mathrm{Cl}+\mathrm{CH}_{2} \mathrm{ClCH}_{2} \mathrm{Cl} \longrightarrow \mathrm{CH}_{2} \mathrm{ClCHCl}+\mathrm{HCl} & \Delta \mathrm{H}=-24 \mathrm{~kJ} / \mathrm{mol} \\
\mathrm{CH}_{2} \mathrm{ClCHCl} \longrightarrow \mathrm{CH}_{2}=\mathrm{CHCl}+\mathrm{Cl} & \Delta \mathrm{H}=95 \mathrm{~kJ} / \mathrm{mol}
\end{array}
$$

After the first proposition of this mechanism by Barton and Howlett $^{39}$, several authors tried to elucidate the kinetics of the system. Strong effects due to chain promotors, for example $\mathrm{O}_{2}$ and $\mathrm{Cl}_{2}$ ' and chain inhibitors such as propylene and vinyl chloride itself were found. Wall effects turned out to be important for initiation as well as termination in the pyrolytic reaction. Holbrook et al. 40 found that the surface to volume ration and the condition of the reactor surface has a strong influence on the conversion rates. In calorimetric measurements Kapralova and semenov ${ }^{41}$ showed that the reaction is constricted to the region near to the walls.

The most common way used up to now to interpret the experimental reaction order and conversion rates is to describe the system including reactions $(1)-(3)$ and the termination step

$$
\mathrm{Cl}+\mathrm{C}_{2} \mathrm{H}_{3} \mathrm{Cl}_{2} \longrightarrow \text { products }
$$

by a number of differential equations using the steady state assumption for the radicals $\mathrm{Cl}$ and $\mathrm{C}_{2} \mathrm{H}_{3} \mathrm{Cl}_{2}$. This results in an expression for the DCE consumption which is first order in DCE:

$$
d[D C E] / d t=\sqrt{k_{1} k_{2} k_{3} / k_{4}}[D C E]
$$


The method, first described in the work of Rice and Herzfeld ${ }^{42}$, ignores, however, some crucial aspects: the initiation is heterogeneous and can therefore not simply be described by reaction (1). For the termination step one should consider additional channels, e.g. the reverse of reaction (3), the recombination of the dichloroethyl-radicals, and processes involving the surface of reactor. Chlorinated ethanes should show a reactive behaviour in radical chains similar to DCE, provided that there is hydrogen bonded in the position of the chlorine-carrying carbon atom. In contrast to this assumption several experimentators investigating the pyrolysis of these compounds found typical non-radical behaviour of some species when adding inhibitors like propene to chloroethane, 1,1dichloroethane, and 1,1,1-chlorodifluoroethane. The last is industrially imporatant because it is the precursor of the monomer vinylidene fluoride. The main reason for the observed preference for the four-center elimination compared to the radical chain route could be the formation of $\delta$-radicals like $\mathrm{CH}_{3}-\mathrm{CF}_{2}$ which are unable to decompose into chain propagation radicals and are therefore acting as recombination partners ${ }^{43}$.

The best way for improving the study of the basic chain behaviour is to start the chain reaction homogeneously under wallfree conditions. RGH laser light sources are ideally suited for this purpose. Their defined wavelength and beam geometry together with the short pulse length allow a controlled start of the chain by photolysis. Illuminating a zone in the middle of the reactor ensures that also the termination steps are homogeneous in the observed region.

It is commonly accepted that the primary step in the photolysis of alkyl chlorides in the spectral region of their continuum absorption is the dissociation of the $\mathrm{C}-\mathrm{Cl}$ bond with a quantum yield near unity ${ }^{44}$. The chemistry of the photochemically induced 


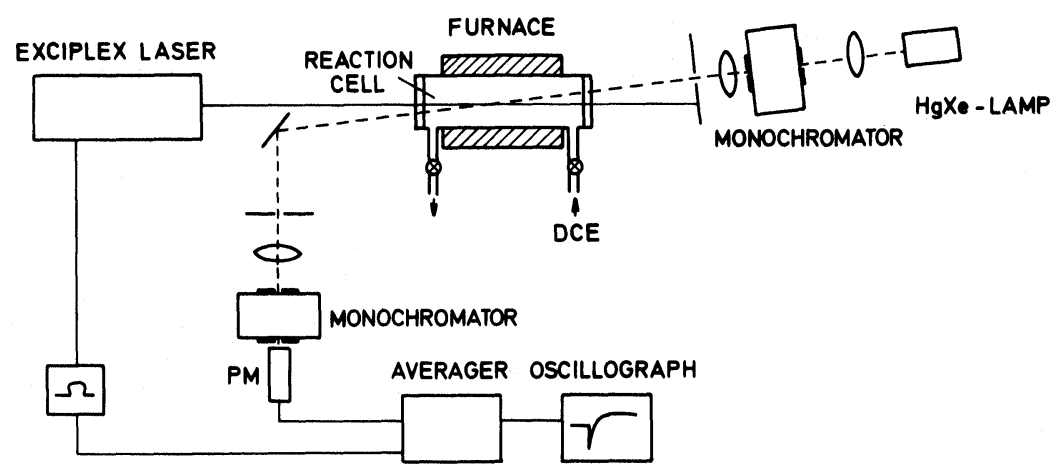

FIGURE 7 Experimental arrangement for the time-resolved study of laser-induced redical chain reactions.

chain reaction should be identical to the thermal reaction. Some recent publications ${ }^{45-47}$ on the photolysis of $1,1,1-\mathrm{C}_{2} \mathrm{H}_{3} \mathrm{Cl}_{3}$ and $1,1-\mathrm{C}_{2} \mathrm{H}_{4} \mathrm{Cl}_{2}$ suggest that additional steps such as the $\boldsymbol{\alpha}$ - or $\boldsymbol{\beta}$ elimination of $\mathrm{HCl}$ or $\mathrm{Cl}_{2}$ should play a role, but in these measurements secondary reactions were not strictly excluded. In our calculations we took the quantum yield for reaction (1) to be $0.9 \pm 0.1$. At sufficiently high temperatures the initial chloroethyl radical will decompose in a short time range compared to the total reaction to yield an additional chlorine atom and ethylene.

Figure 7 shows a schematic of the experimental apparatus for the time resolved measurements. The monitor beam passes near axially along the cell so that the space near the windows is excluded from the observation volume. The absorption signals of the products are detected by the photomuliplier, amplified, digitized in a fast transient recorder (Biomation, 8100) and summed by a signal averager (Tracor, NS-575 A) to enhance S/N. Figure 8 demonstrates a typical signal for the time resolved formation of VC after a laser shot.

From the UV-absorption cross sections $\sigma$, the laser pulse 


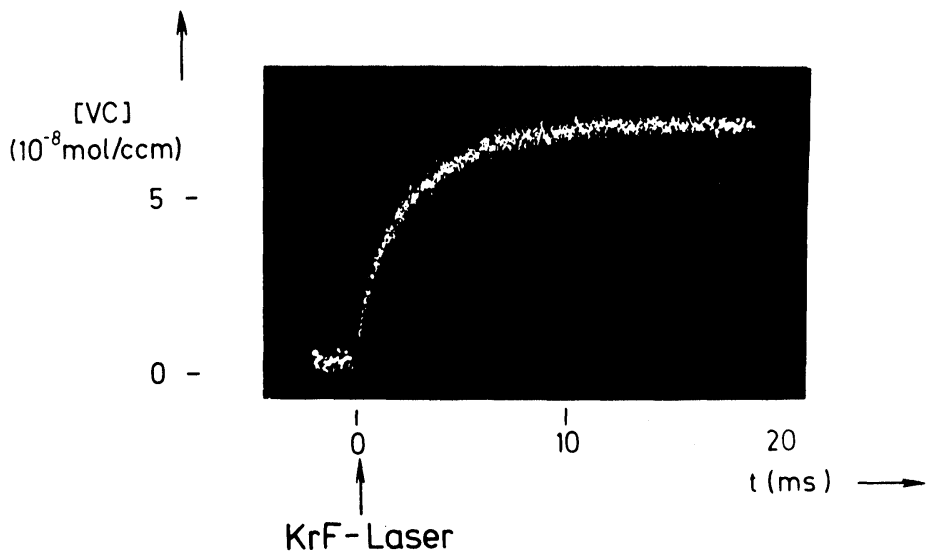

FIGURE 8 UV-absorption signal ( $\mathrm{T}=570 \mathrm{~K}, \mathrm{p}=300$ Torr, $\mathrm{E}_{\mathrm{F}}=188 \mathrm{~mJ}$ ) showing the laser-induced formation of vinilchloride

$E_{L^{\prime}}$ and the amount of product formed, one can calculate the spatially and temporally integrated quantum yield

$$
\phi=E_{L}(\lambda / h C)(1-\exp (-\sigma[D C E] d)) / N_{V C}
$$

$\left([D C E]=\right.$ concentration of the substrate in molecules $/ \mathrm{cm}^{3}, \mathrm{~N}_{\mathrm{VC}}=$ Number of product molecules)

In order to study this effect a series of experiments was carried out varying the laser energy from 5 to $300 \mathrm{~mJ}$ at fixed photolysis wavelength, temperature, and DCE pressure $(\boldsymbol{\lambda}=248 \mathrm{~nm}$, $\mathrm{p}=300$ Torr, $\mathrm{T}=570 \mathrm{~K}$ ). In the double logarithmic plot of quantum yields versus initial radical concentration (Figure 9) one obtains a straight line with a slope of -0.52 . The quantum yield decreases inversely proportional to the square root of start radical concentration.

This result, can be explained by the Rice-Herzfeld mechanism keeping in mind the objections stated in the introduction and the fact that it is formulated for continuous radical formatuon. When a lamp with the radiation density $I_{0}$ is used for photolysis, the 


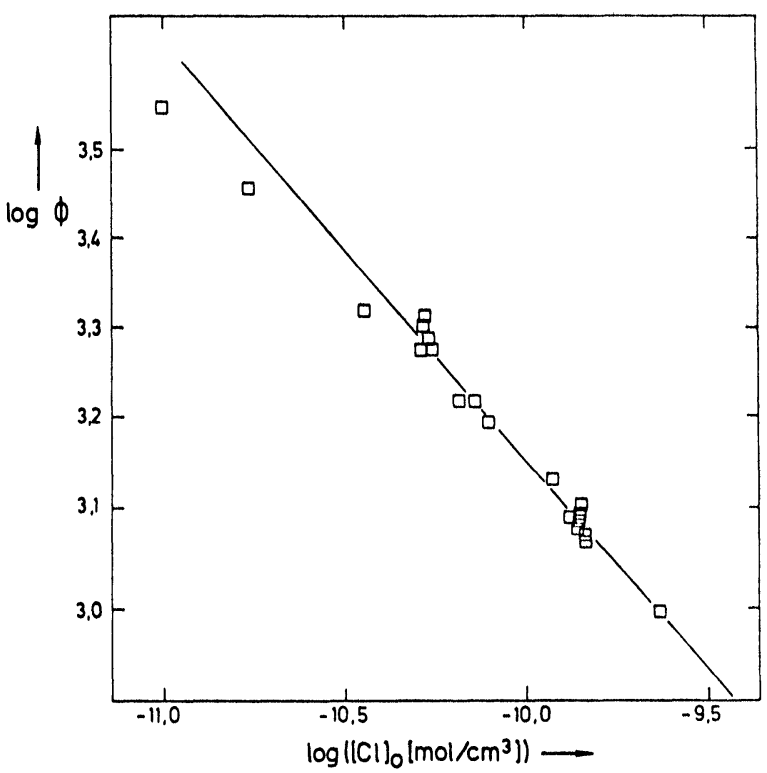

FIGURE 9 Effect of initial radical cincentration of the quantum yield of the laser-induced chain reaction

radical formation at weak absorption may be described by the equation

$\mathrm{d}[\mathrm{Cl}] / \mathrm{dt}=\mathrm{I}_{\mathrm{O}} \cdot \phi_{\mathrm{O}} \cdot \sigma \cdot(\lambda / \mathrm{hC}) \cdot[\mathrm{DCE}]=\mathrm{k}_{1}^{\prime} \mathrm{DCE}$

( $\phi$ = Quantum yield of the primary photolysis step)

with eq. (5) one gets the differential quantum yield

$\phi=(\mathrm{d}[\mathrm{VC}] / \mathrm{dt}) /(\mathrm{d}[\mathrm{Cl}] / \mathrm{dt})=\sqrt{\mathrm{k}_{2} \mathrm{k}_{3} / \mathrm{k}_{1}^{\prime} \mathrm{k}_{4}}$

which is in agreement with the inverse square root dependence found in the experiments. For the apparent activation energy of $\phi$ one gets

$$
-R(d \ln \phi / d t)=1 / 2\left(E_{2}+E_{3}\right) /\left(E_{1},+E_{5}\right)
$$

One would expect from this relation that the quantum yield activation energy is roughly half of the activation energy of step 
because the contributions of the other steps are negligible. In the next section it will be shown that $\mathrm{E}_{3}=83 \mathrm{~kJ} / \mathrm{mol}$.

An additional series of experiments was performed to study the temperature dependence of the quantum yield at a constant conversion rate per laser shot. This has the advantage of working with constant effects like adiabatic cooling or vinyl chloride inhibition. At the highest temperature studied $(720 \mathrm{~K})$ and a low laser energy of $1 \mathrm{~mJ} / \mathrm{cm}^{2}$, we obtained quantum yields of more than $10^{4}$.

Two methods were employed to interpret the measured concentration of the coupled differential equations describing the time behaviour of the different species. Starting with a value for the rate determining step (3), whose rate constant has been determined by several authors by indirect methods we found that the calculated chain lengths were always higher than the experimental ones.

Therefore the time resolved experimental signals as well as the quantum yields were simulated by adjusting $k_{3}$ and introducing additional inhibition reactions. The addition of the 1,2-dichloroethyl radical to vihyl chloride forming an "inert radical" represents a good explanation for the self-inhibiting effect of the product.

$$
\mathrm{C}_{2} \mathrm{H}_{3} \mathrm{Cl}_{2}+\mathrm{C}_{2} \mathrm{H}_{3} \mathrm{Cl} \longrightarrow \mathrm{C}_{4} \mathrm{H}_{6} \mathrm{Cl}_{3}
$$

Under the experimental conditions, reaction (3) is the rate determining step of the chain, i.e. $\mathrm{k}_{3} \ll \mathrm{k}_{2}\left[\mathrm{C}_{2} \mathrm{H}_{4} \mathrm{Cl}_{2}\right]$ at pressures of some hundred Torrs. After the short laser pulse ( $30 \mathrm{~ns}$ ) an equilibrium between the carrier radicals $\mathrm{C}_{2} \mathrm{H}_{3} \mathrm{Cl}_{2}$ and $\mathrm{Cl}$ is quickly established $\left(\tau=1 /\left(\mathrm{k}_{2}\left[\mathrm{C}_{2} \mathrm{H}_{4} \mathrm{Cl}_{2}\right]\right)<100 \mathrm{~ns}\right)$ for which the equation

$$
\left[\mathrm{C}_{2} \mathrm{H}_{3} \mathrm{Cl}{ }_{2}\right] /[\mathrm{Cl}]=\mathrm{k}_{2}\left[\mathrm{C}_{2} \mathrm{H}_{4} \mathrm{Cl}_{2}\right] /[\mathrm{Cl}]
$$

is valid. After this short period the sum of radical concentrations in nearly equal to the start cincentration of $\mathrm{Cl}$ atoms produced by the laser pulse 


$$
\left[\mathrm{C}_{2} \mathrm{H}_{3} \mathrm{Cl}_{2}\right]_{\tau} \approx[\mathrm{Cl}]_{\mathrm{O}}
$$

At the time $\tau$ the formation of vinyl chloride can be described by

$$
(\mathrm{d}[\mathrm{VC}] / \mathrm{dt})_{\tau}=\mathrm{k}_{3}\left[\mathrm{C}_{2} \mathrm{H}_{3} \mathrm{Cl}_{2}\right] \approx \mathrm{k}_{3}[\mathrm{Cl}]_{\circ}
$$

If the concentration time profiles are simple exponential with a time conctant $\mathrm{k}_{\mathrm{f}}$

$$
\begin{aligned}
& {[V C]=[V C]_{\infty}\left(1-\exp \left(-k_{f} t\right)\right)} \\
& d[V C] / d t=[V C]_{\infty} \cdot k_{f} \cdot \exp \left(-k_{f} t\right)
\end{aligned}
$$

and at $t=0 \quad(\mathrm{~d}[\mathrm{VC}] / \mathrm{dt})_{t=0}=[\mathrm{VC}]_{\infty} \mathrm{k}_{\mathrm{f}}$

$$
\mathrm{k}_{3}=\left([\mathrm{VC}]_{\infty} /[\mathrm{Cl}]_{\mathrm{O}}\right) \cdot \mathrm{k}_{\mathrm{f}}=\mathrm{L} \cdot \mathrm{k}_{\mathrm{f}}
$$

The microscopic duration of a chain cycle (determined by the slowest step) is reflected in the macroscopic total reaction time with the chain length $L$ acting as an extension coefficient. The advantage of the analytical method is that it is not necessary to know the termination reactions in detail. Any inhibition reaction shortens the total reaction time but also the chain length so that the value of $\mathrm{k}_{3}$ remains constant. The algorithm was tested experimentally by a series of runs with fixed temperature and pressure and varying irradiation intensity. The experiments showed that the decrease of the chain length with higher initial radical concentration is paralleled by the increase of reaction time so that the arithmetic product of both remains constant over the whole range of laser energy. Figure 10 compiles data for the change of the uni. molecular rate constant $\mathrm{k}_{3}$ when an inert gas $\left(\mathrm{N}_{2}\right)$ was added to 60 Torr of DCE up to a total pressure of 600 Torr. The reaction rate is strongly pressure dependent in this region. In the double $\operatorname{logarithmic}$ plot $\log \mathrm{k}_{3} / \log \mathrm{p}$ one obtains a straight line with a slope of 0.5 .

The Arrhenius diagram of the measurements at 300 Torr DCE 


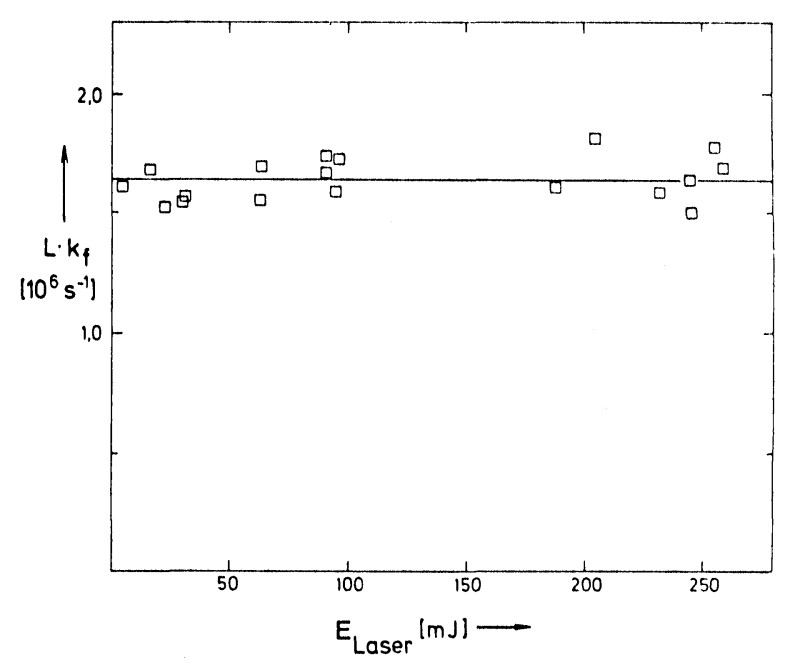

FIGURE 10 Determination of $\mathrm{k}_{3}$ from overall reaction data between 520 and $720 \mathrm{~K}$ shows a decline of activation energy with temperature. There are two reasons for this effect. First, when moving to higher temperatures at constant pressures, the unimolecular reaction shifts more into the second order region where the activation energy is lower. Secondly, at higher temperatures, the rate of $\mathrm{k}_{3}$ increases so that this step is no longer strictly rate determining. Therefore the low temperature values are taken to determine the Arrhenius parameters. In the region $520-570 \mathrm{~K}$, one gets the expression

$$
\mathrm{k}_{3}=(6.5 \pm 2) \cdot 10^{13} \cdot \exp (-83 \pm 3 \mathrm{~kJ} / \mathrm{mol} / \mathrm{RT})
$$

Photolysing CDFE with an ArF*-Laser (193 nm) at pressures around 40 Torr we found only small quantum yildes $(0.3$ at $673 \mathrm{k}, 5.4$ at $738 \mathrm{~K})$. Two effects might influence the photolysis yield: firstly, the primary photolytic step may be dominated by the molecular elimination of $\mathrm{HCl}$ as measured at $147 \mathrm{~nm}$ and $123.6 \mathrm{~nm}$ by Ichimura et al. $^{48}$. Secondly, the decomposition rate of the intermediate radical 


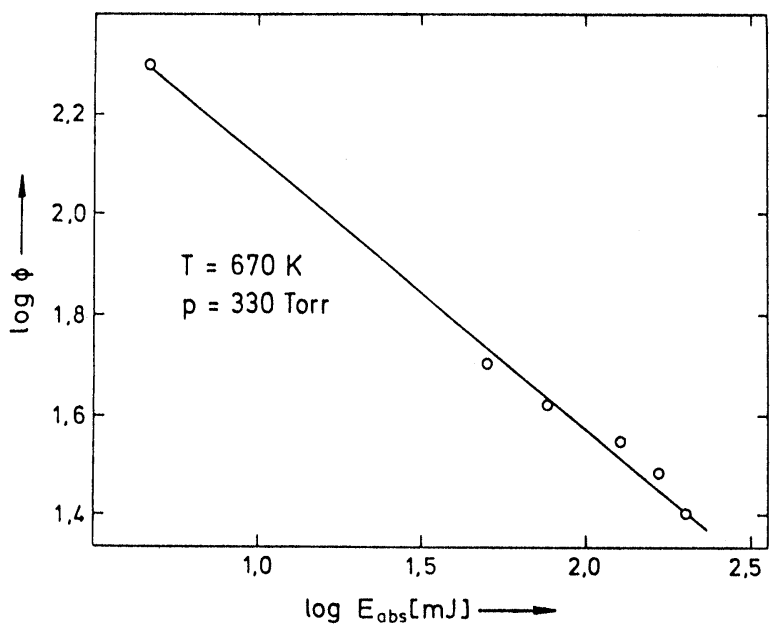

FIGURE 11 Effect of initial radical concentration of $\Phi$ in VDF formation

$$
\mathrm{CF}_{2} \mathrm{Cl}-\mathrm{CH}_{2}+\mathrm{M} \longrightarrow \mathrm{CH}_{2} \mathrm{CF}_{2}+\mathrm{Cl}+\mathrm{M}
$$

is assumed to have a higher activation energy relative to the $\mathrm{CH}_{2} \mathrm{Cl}-\mathrm{CHCl}$ radical.

Additional experiments were carried out using $\mathrm{CCl}_{4}$ as absorber and changing the laser wavelength to the $\mathrm{KrF}^{*}$ line at $248 \mathrm{~nm}$. $\mathrm{CCl}_{4}$ is known to be a suitable initiator of the radical reaction of $1,1,1-\mathrm{C}_{2} \mathrm{H}_{3} \mathrm{ClF}_{2}$. Figure 11 shows the measured quantum yields for VDF formation as a function of absorbed laser energy which was controlled by the amount of $\mathrm{CCl}_{4}$ added to the sustrate. At comparable initial radical concentrations the quantum yields are at least an order of magnitude higher than for the ArF* photolysis of the pure compound. A significant increse in the chain length $\left(\phi>10^{5}\right)$ for the laser induced formation of $\mathrm{VC}$ is observed using $\mathrm{Cl}_{2}$ as absorber and changing the laser wavelength to the $\mathrm{XeCl}$ line at $308 \mathrm{~nm}$ (see Figure 12). 


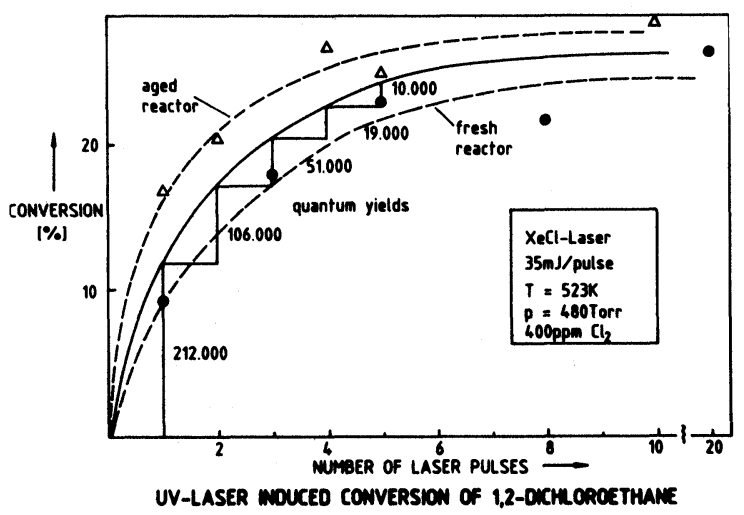

FIGURE 12 Effect of $\mathrm{Cl}_{2}$ addition on the laser-induced quantum yield of vc-formation

$\underline{\text { ACKNOWLEDGEMENTS }}$

The financial support by the Deutsche Forschungsgemeinschaft (Sonderforschungsbereich 123, Stochastische, mathematische Modelle), is gratefully acknowledged.

\section{REFERENCES}

1. F. J. WEINBERG, Fifteenth Symposium (International) on Combustion (The Combustion Institute, 1975), p. 1 .

2. J. WARNATZ, Ber. Bunsenges. Phys. Chem., 87, 1008 (1983)

3. K. KLEINERMANNS, J. WOLFRUM, J. Chem. Phys., 80, 1446 (1984)

4. K. KLEINERMANNS, J. WOLFRUM, Appl. Phys., B34, 5 (1984)

5. K. KLEINERMANNS, J. WOLFRUM, Chem. Phys. Lett., 104, 157 (1984)

6. K. KLEINERMANNS, E. LINNEBACH, Appl. Phys. B (to be published, 1984)

7. K. KLEINERMANNS, R. SCHINKE, J. Chem. Phys., 80, 1440 (1984)

8. C. F. MELIUS, R. J. BLINT, Chem. Phys. Lett. , 64, 183 (1979)

9. P. PECHUKAS, J. C, LIGHT, C. RANKIN, J. Chem. Phys., 44, 794 (1966)

10. J. A. MILLER, J. Chem. Phys., 74,5120 (1981)

11. G. L. SCHOTT, Combust. Flame, 21, 357 (1973)

12, Th. JUST, G. FRANK, (to be published) 
13. D. L. BAULCH, D. D. DRYSDALE, D. G. HORNE, Fourteenth Symposium (International) on Combustion (The Combustion Institute, 1973), p. 107 .

14. C. T. BOWMAN, Fifteenth Symposium (International) on Combustion (The Combustion Institute, 1975), p. 869.

15. C. COBOS, H. HIPPLER, J. TROE, J. Chem. Phys., (in press, 1984)

16. J. A. MILLER, N. J. BROWN, J. Phys. Chem., 86, 772 (1982)

17. T. H. DUNNING jr., S. P. WALCH, M. M. GOODGAME, J. Chem. Phys., 74, 3482 (1981)

18. S. N. RAI D. G. TRUHLAR, J. Chem. Phys., 79, 6046 (1983)

19. M. QUACK, J. TROE, J. Chem. Soc. Spec. Period. Report Gas Kinet. Energy Transfer, 2, 175 (1977)

20. N. COHEN, K. R. WESTBERG, Chemical Kinetic Data Sheets for High Temperature Chemical Reactions, Aerospace Report No. ATR 82(7888)-3, El Segundo (1982)

21. F. C. LONDON, Probleme der Modernen Physik (Hirzel, Leipzig, 1928), p. 104.

22. P. SIEGBAHN, B. LIU, J. Chem. Phys., 68, 2457 (1978)

23. D. G. TRUHLAR, C. J. HOROWITZ, J. Chem. Phys. , 68, 2460 (1978)

24. E. B. GORDON, B. I. IWANOV, A. P. PERMINOV, V. G. BALALAEV, A. N. PONOMAREV, V. V. FITATOV, Chem. Phys. Lett. , 58, 425 (1978); V. B. ROZENSHTEIN, Yu. M. GERSHENZON, A. V. IVANOV, S. I. KUCHERJAVII, Chem. Phys. Lett. , 105, 423 (1984)

25. M. KNEBA, U. WELLHAUSEN, J. WOFRUM, Ber. Bunsenges. Phys. Chem., 83, 940 (1979)

26. G. P. GLASS, N. B. CHATURVEDI, J. Chem. Phys., 77, 3478 (1982)

27. U. WELLHAUSEN, Dissertation Universität Göttingen (1984) U. WELlhausen, J. WOlfRUM, Phys. Rev. Lett. (to be publ. 1984)

28. E. POLLAK, Chem. Phys. Lett., 80, 45 (1981)

29. E. POLLAK, R. E. WYATT, J. Chem. Phys., 78, 4464 (1983)

30. R. B. WALKER, E. F. HAYES, J. Phys. Chem., 87, 1255 (1983)

31. H. R. MAYNE, J. P. TOENNIES, J. Chem. Phys., 75, 1794 (1981)

32. J. M. BOWMAN, U. T. LEE, R. B. WALKER, J. Chem. Phys. , 79, 3742 (1983)

33. N. ABU SALBI, D. J. KOURI, Y. SHIMA, M. BAER, Chem. Phys. Letters (to be published, 1984)

34. D. D. GERRITY, J. J. VALENTINI, J. Chem. Phys. (to be publ. 1984)

35. C. T. RETTNER, E. E. MARINERO, R. N. ZARE, J. Chem. Phys. (to be publ. 1984)

36. R. GOTTING, H. R. MAYNE, J. P. TOENNIES, J. Chem. Phys. (to be publ. 1984)

37. N. C. BLAIS, D. G. TRUHLAR, Chem. Phys. Lett., 102, 120 (1983)

38. H. BILTZ, Ber. , 35, 3524 (1902)

39. D. H. R. BARTON, K. E. HOWLETT, J. Chem. Soc., 148, 155 (1949) 
40. K. A. HOLBROOK, R. W. WALKER, W. R. WATSON, J. Chem. Soc. (B), 577 (1971)

41. G. A. KAPRALOVA, N. N. SEMENOV, Russ. J. Phys. Chem., 37, 35 and $15 u$ a $\rightarrow 3$ )

42. F. O. RICE, K. F. HERZFELD, J. A. C. S., 56, 284 (1934)

43. G. J. MARTENS, M. GODFROID, R. DECELLE, J. VERBEYST, Int. J. Chem. Kin. , 4, 645 (1972)

44. J. G. CALVERTS, J. N. PITTS, Photochemistry (Wiley, New York, 1967)

45. T. FUJIMOTO, J. H. M. WIJNEN, J. Chem. Phys., 56, 4032 (1972)

46. T. S. YUAN, M. J. J. WIJNEN, Ber. Bunsenges. Phys. Chem., 81, 310 (1977)

47. S. HAUTECLOQUE, J. Photochem., 12, 187 (1980)

48. T. ICHIMURA, A. W. KIRK, E. TSCHUIKOW-ROUX, Int. J. Chem. Kin., 9, 696 (1977)

T. ICHIMURA, A. W. KIRK, E. TSCHUIKOW. ' $\mathrm{x}$, J. Phys. Chem. , 81, 2040 (1977) 